\title{
Opportunities to Improve the Digital Skills of Health Care Specialists
}

\author{
Oskars Rasnacs ${ }^{1}$ MSc. math.; Maris Vitins ${ }^{2}$ Dr. sc. comp. \\ The University of Economics and Culture, Latvia ${ }^{1}$ \\ Faculty of Computing, University of Latvia, Latvia ${ }^{2}$ \\ oskars.rasnacs@inbox.lv ${ }^{1}$; maris.vitins@lu.lv²
}

\begin{abstract}
The authors investigate the opportunities to improve the digital skills of graduates from the Latvian Universities of health. The digital skills are one of the most necessary preconditions for a productive cooperation in society of information. In Latvia, the digital skills of medical staff are important and urgent, especially in association with the e-health system implementation. The authors continue and develop their previous research by involving new participants and improving the applied models. The authors have already found out in their previous studies that the digital skills of graduates of health care specialities are formed in informatics and statistics courses, and achievements in these courses affect the application of the information and communication technology and statistics in their professional work. This statement is an indication that there are opportunities to improve these skills, namely, the acquisition of informatics and statistics courses must be improved. For students the first professional work of a relatively large volume is diploma paper. In the recent research, the authors also continue finding out evidence of the important role of information and statistics courses for the use of information and communication technologies and statistics in professional work of graduates of health care specialities.
\end{abstract}

Keywords: health care, information and communication technology, statistics, university education.

\section{Introduction}

The authors (Rasnacs, Vitins, 2013) started their research in 2012 by inquiring graduates of $2001-2012$ of the Riga Stradins University and Riga Technical University. In 2016, graduates (2005 - 2016) of the Red Cross Medical College of Riga Stradins University were involved in the research (Rasnacs, Vitins, 2017).

The basis of the research is inquiry. About 300 graduates of health care specialities were inquired in the internet environment. The authors were interested in how the results of informatics and statistics courses affect the prediction of the results relevant to professional work. Data were obtained from 114 graduates. Descriptive statistics and Spearman correlation analysis were carried out. The obtained correlation coefficients were not so high to form linear models; therefore, nonlinear models were formed. It should be mentioned that assessments of the informatics and statistics courses and defense of diploma paper were high ( $\mathrm{Me}=8$ according to 10 -point system).

The aim of the research: to determine whether by improving some assessments the other assessments will be also improved.

\section{Methodology}

Hypothesis of the research: improvement of the assessment of informatics and statistics courses improves the use of information and communication technology and statistics in professional work.

The authors obtained data from 114 graduates of health care specialities of the Latvian higher education institutions. The authors asked about the following issues:

- higher education institution graduated;

- speciality;

- year of graduation;

- $\mathrm{x}_{1}-$ mark in the informatics and statistics course (if there are several study courses, then the rounded average mark);

- $\mathrm{x}_{2}$ - self-assessment of your knowledge of informatics and statistics;

- $\mathrm{x}_{3}$ - assessment of diploma paper defense;

- $\mathrm{x}_{4}$ - self-assessment of diploma paper;

- $\mathrm{x}_{5}$ - your opinion - how much the defense of your diploma paper results were affected by the acquisition of informatics and statistics course;

- $\mathrm{x}_{6}-$ your opinion - how useful the acquisition of informatics and statistics course is in your professional work; 
- $\mathrm{x}_{7}-$ your opinion - how much the defense of your diploma paper results were affected by other study courses;

- $\mathrm{x}_{8}$ - your opinion - how much the defense of your diploma paper results were affected by individual consultations on informatics and statistics issues during its working out (if you attended any).

The students' data did not correspond to the normal distribution (Kolmogorov - Smirnov test, $\mathrm{p}<0.001$ ), except $\mathrm{x}_{6}$ (McCrum-Gardner, 2008; Moore, 2007). Therefore, a nonparametric statistic was applied.

It should be taken into consideration that courses and diploma paper at the Latvian higher education institutions are assessed in scores of 10-point system. A successful assessment score is from four to ten points. For a student to be allowed to work out his/her diploma paper, the assessment $\mathrm{x}_{1}$ must be at least 4. For a student to graduate, the assessment $x_{3}$ must be at least 4 . The other assessments may be from 1 to 10 , the authors assumed that 0 value means an impossible assessment. If a student receives $x_{1}$ a failure assessment 3, then $\mathrm{x}_{3}$ should be 3 , and other assessments 0 .

\section{Results and Discussion}

Statistics of the survey variables are shown in Figure 1.

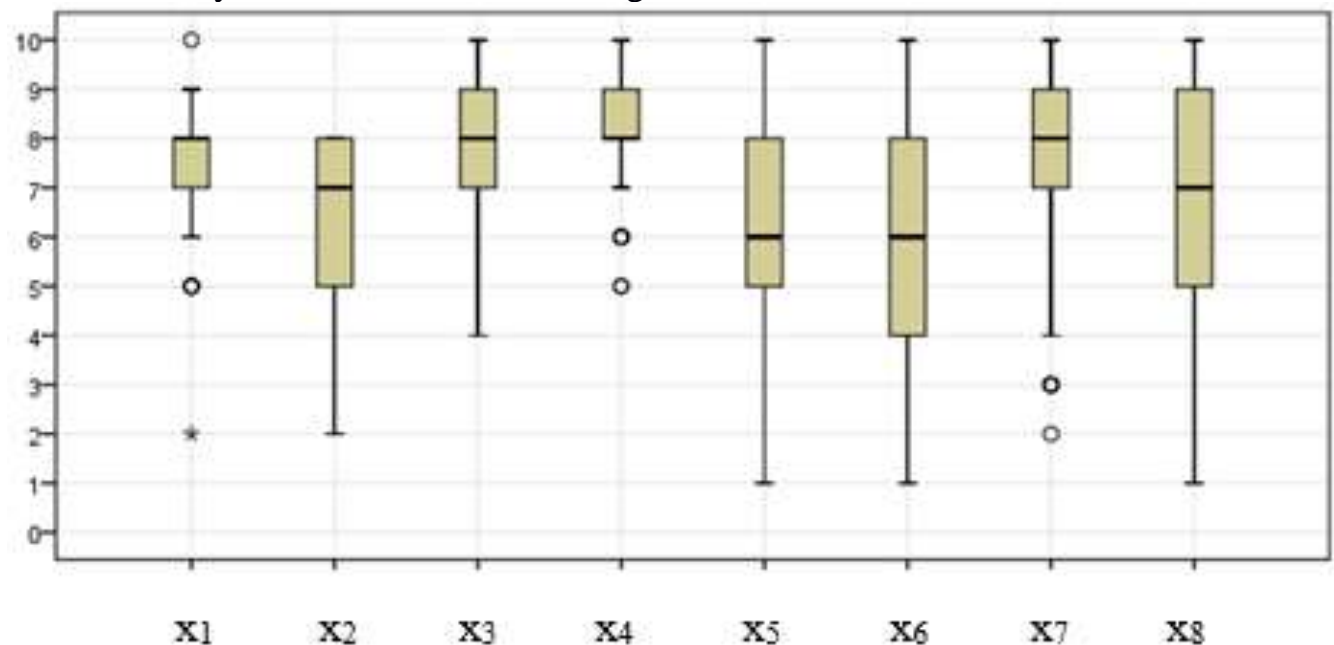

Figure 1. Factors influencing the formation of a grade.

Correlation coefficients between $\mathrm{x}_{1}(\max 0.239)$ and $\mathrm{x}_{2}(\max 0.295)$ are not so high in order to form linear models (Table 1). The sign * means that correlation is significant at the 0.05 level (2-tailed). The sign $* *$ means that correlation is significant at the 0.01 level (2-tailed).

Correlation coefficients

Table 1

\begin{tabular}{|c|c|c|c|c|c|c|}
\hline \multirow{2}{*}{ Variables } & \multicolumn{3}{|c|}{$\mathbf{x}_{\mathbf{1}}$} & \multicolumn{3}{|c|}{$\mathbf{x}_{\mathbf{2}}$} \\
\cline { 2 - 7 } & $\mathbf{r}$ & $\mathbf{p}$ & $\mathbf{n}$ & $\mathbf{r}$ & $\mathbf{p}$ & $\mathbf{n}$ \\
\hline $\mathrm{x}_{3}$ & $0.209^{*}$ & 0.040 & 97 & 0.117 & 0.243 & 101 \\
\hline $\mathrm{x}_{4}$ & $0.231^{*}$ & 0.023 & 97 & $0.243^{*}$ & 0.014 & 101 \\
\hline $\mathrm{x}_{5}$ & $0.239^{*}$ & 0.018 & 97 & $0.269^{* *}$ & 0.006 & 101 \\
\hline $\mathrm{x}_{6}$ & 0.173 & 0.091 & 97 & $0.295^{* *}$ & 0.003 & 101 \\
\hline $\mathrm{x}_{7}$ & 0.152 & 0.136 & 97 & -0.049 & 0.630 & 101 \\
\hline $\mathrm{x}_{8}$ & 0.199 & 0.059 & 91 & -0.032 & 0.759 & 95 \\
\hline
\end{tabular}


Poor correlation between variables $\mathrm{x}_{1}$ and $\mathrm{x}_{5}$ is drawn in Figure 2 and between variables $\mathrm{x}_{2}$ and $\mathrm{x}_{6}$ in Figure 3.

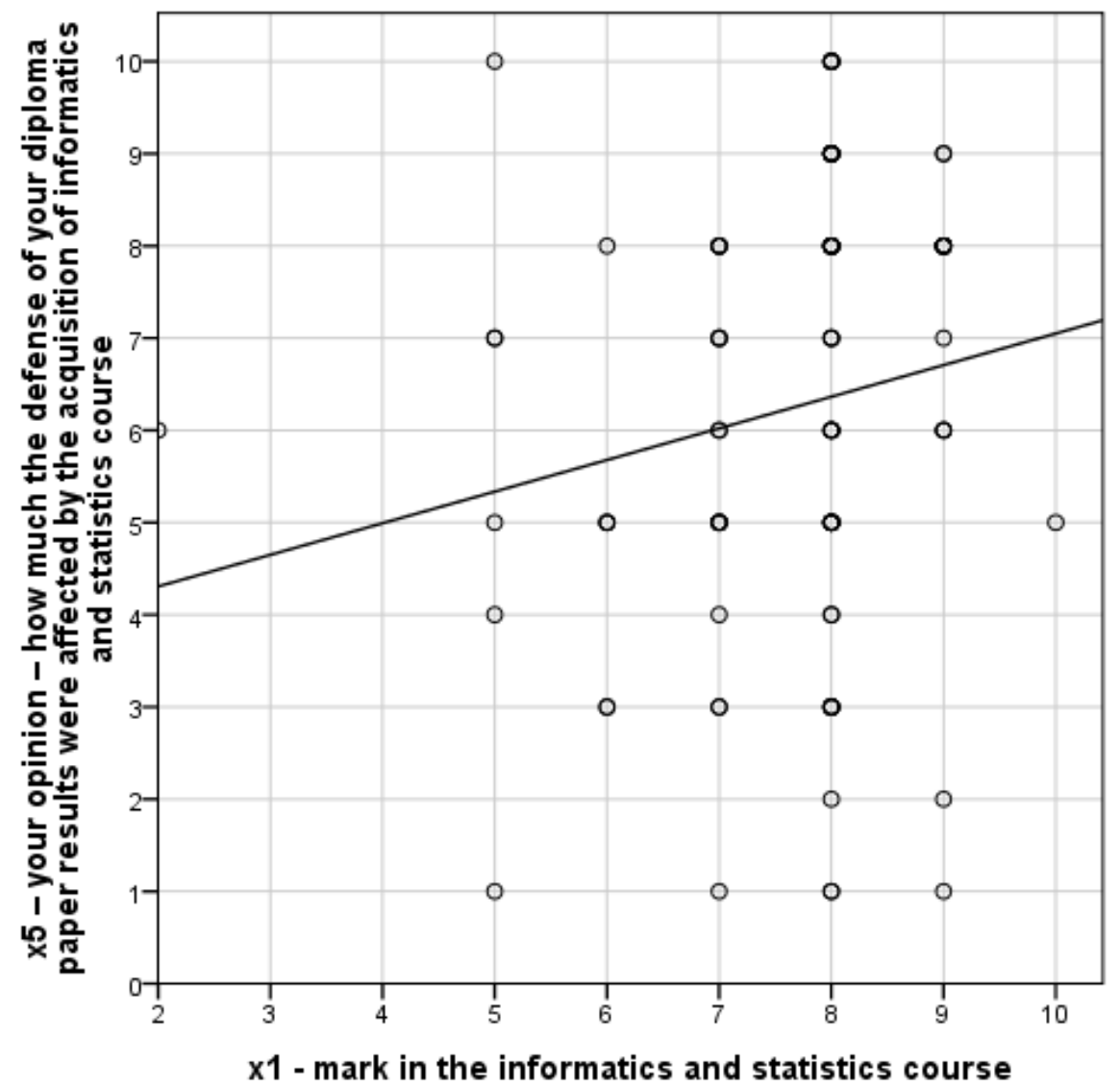

Figure 2. Correlation between variables $\mathrm{x}_{1}$ and $\mathrm{x}_{5}$.

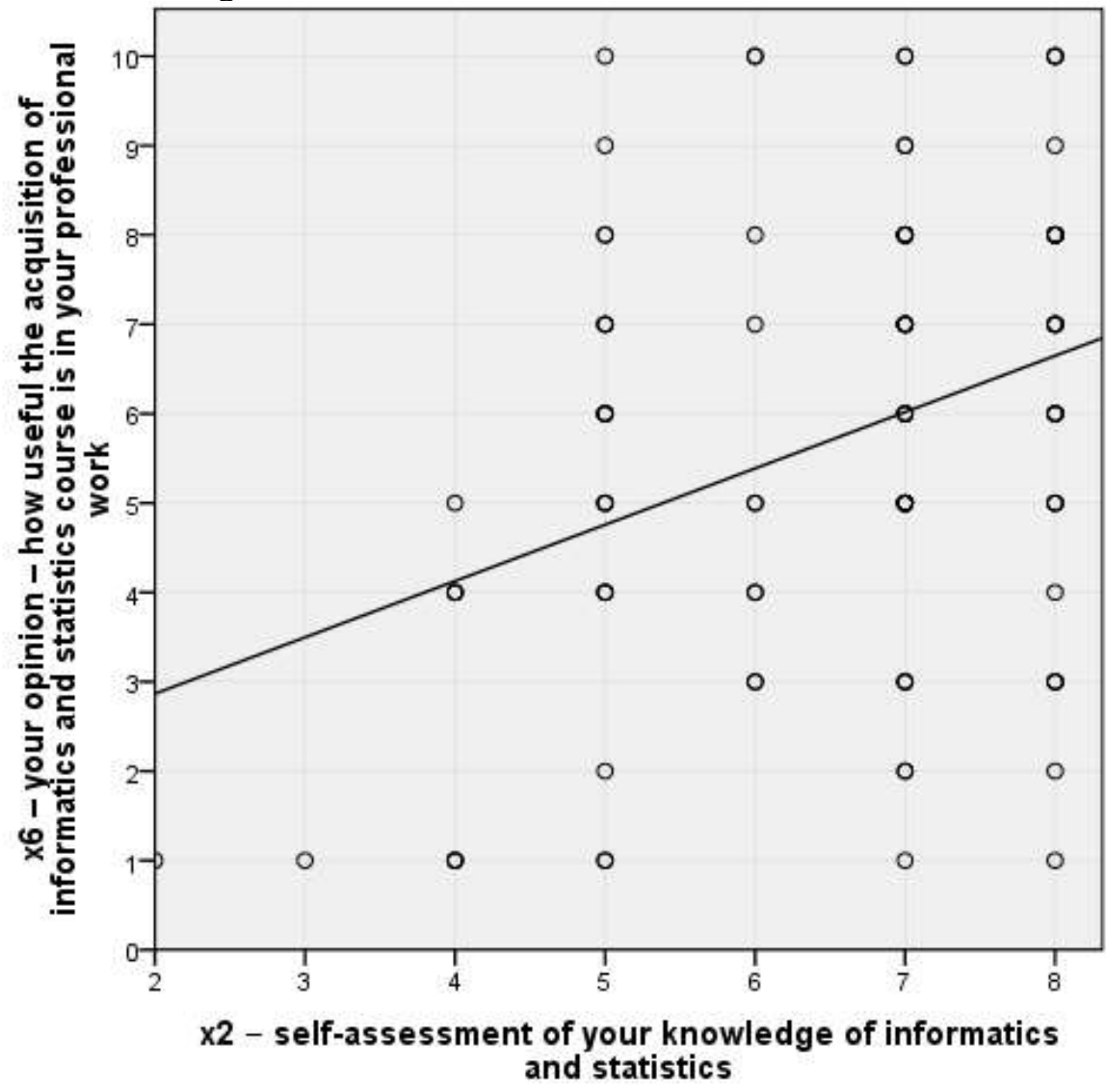

Figure 3. Correlation between variables $\mathrm{x}_{1}$ and $\mathrm{x}_{5}$. 
By using the traditional multiple linear regression, the following model was obtained:

$$
\mathrm{X}_{3}=5.65+0.232 \mathrm{x}_{1}+0.093 \mathrm{x}_{2}, \mathrm{R}^{2}=0.058
$$

However, this model is not applicable for prediction because:

- determination coefficient is low;

- both factors $\mathrm{x}_{1}$ and $\mathrm{x}_{2}$ are not statistically significant ( $\left.\mathrm{p}>0.05\right)$;

- students who received $x_{1}=3$ points and self-assessment $x_{2}=1$, prediction of diploma paper grade is 6 , which is incorrect.

Therefore, the authors were trying to find ways how to develop nonlinear models. Models were developed by using the several methods.

1. In Latvia, a successful assessment score is $4-10$ points; for a student to be allowed to work out the diploma paper, assessments of all courses must be at least 4 .

2. Failure assessments $(1,2,3) \mathrm{x}_{1}$ (students' grades in informatics and statistics courses) and $\mathrm{x}_{3}$ (assessment of diploma paper defense) were identified as 3 in order to attach the model to the starting point of the coordinates; by subtracting 3 from the failure assessment, 0 is obtained.

3. Multiplication $\left(\mathrm{x}_{1}-3\right) \mathrm{x}_{2}\left(\mathrm{x}_{2}\right.$ : self-assessment of students' knowledge and skills in informatics and statistics) in the models was used in order to obtain a real fact: if the assessment of informatics and statistics courses was a failure -3 , then the multiplier is $x_{1}-3$, consequently multiplication is $\left(\mathrm{x}_{1}-3\right) \mathrm{x}_{2}$ irrespective of $\mathrm{x}_{2}$ is 0 .

4. In was used in the models in order to approximate the data to the normal distribution.

5. 1 was added to the expression $\left(\mathrm{x}_{1}-3\right) \mathrm{x}_{2}$, in case of the failure (when multiplication is 0 ), $\ln$ could be calculated, that is 0 .

6. Using the above-mentioned assumptions, models were developed in the MS Excel environment with the Data Analysis/Regression tool.

The following mathematic models were obtained not using the logarithm (Table 2) and using the logarithm (Table 3).

Table 2

\section{Linear mathematic models}

\begin{tabular}{|c|c|c|c|c|}
\hline ID & $\mathbf{n}$ & Model & $\mathbf{R}^{\mathbf{2}}$ & Error \\
\hline 1 & 96 & $\mathrm{x}_{3}=0.150\left(\mathrm{x}_{1}-3\right) \mathrm{x}_{2}+3$ & 0.876 & $20 \%$ \\
\hline 2 & 96 & $\mathrm{x}_{4}=0.239\left(\mathrm{x}_{1}-3\right) \mathrm{x}_{2}$ & 0.901 & $26 \%$ \\
\hline 3 & 96 & $\mathrm{x}_{5}=0.189 *\left(\mathrm{x}_{1}-3\right) \mathrm{x}_{2}$ & 0.848 & $73 \%$ \\
\hline 4 & 96 & $\mathrm{x}_{6}=0.175 *\left(\mathrm{x}_{1}-3\right) \mathrm{x}_{2}$ & 0.826 & $38 \%$ \\
\hline 5 & 96 & $\mathrm{x}_{7}=0.216 *\left(\mathrm{x}_{1}-3\right) \mathrm{x}_{2}$ & 0.855 & $31 \%$ \\
\hline 6 & 90 & $\mathrm{x}_{8}=0.188 *\left(\mathrm{x}_{1}-3\right) \mathrm{x}_{2}$ & 0.772 & $236 \%$ \\
\hline
\end{tabular}

Logarithmic mathematic models

Table 3

\begin{tabular}{|c|c|c|c|c|}
\hline ID & $\mathbf{n}$ & Model & $\mathbf{R}^{2}$ & Error \\
\hline 1 & 96 & $\mathrm{x}_{3}=1.475 *\left(\ln \left(\mathrm{x}_{1}-3\right) \mathrm{x}_{2}+1\right)+3$ & 0.940 & $12 \%$ \\
\hline 2 & 96 & $\mathrm{x}_{4}=2.373 *\left(\ln \left(\mathrm{x}_{1}-3\right) \mathrm{x}_{2}+1\right)$ & 0.977 & $13 \%$ \\
\hline 3 & 96 & $\mathrm{x}_{5}=1.837 *\left(\ln \left(\mathrm{x}_{1}-3\right) \mathrm{x}_{2}+1\right)$ & 0.882 & $71 \%$ \\
\hline 4 & 96 & $\mathrm{x}_{6}=1.694 *\left(\ln \left(\mathrm{x}_{1}-3\right) \mathrm{x}_{2}+1\right)$ & 0.853 & $37 \%$ \\
\hline 5 & 96 & $\mathrm{x}_{7}=2.149 *\left(\ln \left(\mathrm{x}_{1}-3\right) \mathrm{x}_{2}+1\right)$ & 0.930 & $16 \%$ \\
\hline 6 & 90 & $\mathrm{x}_{8}=1.821 *\left(\ln \left(\mathrm{x}_{1}-3\right) \mathrm{x}_{2}+1\right)$ & 0.821 & $229 \%$ \\
\hline
\end{tabular}

In the column $n$, the number of useful data of variables involved in the model is presented. In the column Model, there is the mathematic model equation. In the column $R^{2}$, the determination coefficient is given percentage of the dependent variable dispersion that the model explains, for example, if $\mathrm{R}^{2}$ is 0.876 , then $87.6 \%$. In the column Error, there is the mean relative error, which resulted approbating the models. 
The relative error was calculated by the formula:

$$
R=\frac{\left|y_{p}-y_{r}\right|}{y_{r}}
$$

where $\quad y_{p}$ - predicted value by the model;

$$
\mathrm{y}_{\mathrm{r}}-\text { real value. }
$$

Let us look at the example how to work with a model for the prediction of the diploma paper assessment. For example, for a student $\mathrm{x}_{1}=7$ (grades in informatics and statistics courses), $\mathrm{x}_{2}=8$ (self-assessment of students' knowledge and skills of informatics and statistics).

$$
\begin{aligned}
& \mathrm{x}_{3}=0.150(7-3) * 8+3 \approx 8 \\
& \mathrm{x}_{3}=1.475 *(\ln (7-3) * 8+1)+3=8.158 \approx 8
\end{aligned}
$$

Consequently, the prediction of the diploma paper defense assessment of the above-mentioned student is 8 with both types of models.

There is a tendency that for those graduates who have a low informatics and statistics courses assessment, majority of other assessments are also low, and vice versa. Let us have a closer look at the cases and what values gave logarithmic models due to higher coefficients of determination $\mathrm{R}^{2}$. In this respect, we will discuss three situations of each model:

- assessment is average 5;

- assessment is good 7;

- assessment is excellent 10 .

Results of logarithmic model predictions

Table 4

\begin{tabular}{|c|c|c|c|}
\hline ID & Average & Good & Excellent \\
\hline $\mathrm{x}_{1}$ & 5 & 7 & 10 \\
\hline $\mathrm{x}_{2}$ & 5 & 7 & 10 \\
\hline $\mathrm{x}_{3}$ & 7 & 8 & 9 \\
\hline $\mathrm{x}_{4}$ & 6 & 8 & 10 \\
\hline $\mathrm{x}_{5}$ & 4 & 6 & 8 \\
\hline $\mathrm{x}_{6}$ & 4 & 6 & 7 \\
\hline $\mathrm{x}_{7}$ & 5 & 7 & 9 \\
\hline $\mathrm{x}_{8}$ & 4 & 6 & 8 \\
\hline
\end{tabular}

In Table 4 , in the lanes $\mathrm{x}_{1}-\mathrm{x}_{2}$ there are values of independent variables. In the lanes $\mathrm{x}_{3}-\mathrm{x}_{8}$, values of dependent variables are given. These are prediction results. In the column Average, assessments are average, in the column Good, assessments are good, in the column Excellent, assessments are excellent. Not always it is the maximum or minimum value, for example, if $x_{1}$ and $x_{2}$ are 10 , then $x_{3}$ is predicted 9 .

\section{Conclusions}

- Effect of the acquisition of the informatics and statistics courses on the diploma paper and professional work was investigated by means of the inquiry of graduates of health care specialities of the higher education institutions.

- Assessments of the informatics and statistics courses and diploma paper defense are high.

- Models obtained by using logarithms give more precise predictions.

- At the higher education institutions, attention should be paid to the acquisition of informatics and statistics courses as good as possible. Good knowledge and skills in these courses will result in a good assessment of diploma paper defense and good achievements in the usage of information and communication technology and statistics in professional work. 


\section{Acknowledgements}

The research was developed under the University of Latvia contract no. AAP2016/B032 "Innovative information technologies".

\section{Bibliography}

1. McCrum-Gardner E. (2008). Which is the correct statistical test to use? British Journal of Oral and Maxillofacial Surgery, 46(1), 38 - 41.

2. Moore D. S. (2007). The basic practice of statistics. (4th ed.). New York: W. H. Freeman and Company. Retrieved from https://pdfs.semanticscholar.org/84df/48f2e9808ea7a978fb8a8a426c392d8a02b7.pdf

3. Rasnacs O., Vitins M. (2013). Assesing Computer Skills in Scientific Research on the Basis of Expert Views. In B. Briede (Ed.), International Scientific Conference Proceedings Rural. Environment. Education. Personality, 6. Jelgava: LLU, TF, 339-346. Retrieved from http://llufb.llu.lv/conference/REEP/2013/Latvia-Univ-Agricult_REEP_2013_ISSN_2255-808X$\underline{339-346 . p d f}$

4. Rasnacs O., Vitins M. (2017). The Assessments of Study Courses Influence on the Assessments of Qualification Work. In V. Dislere (Ed.), International Scientific Conference Proceedings Rural. Environment. Education. Personality, 10. Jelgava: LLU, TF, 151-157. Retrieved form http://llufb.llu.lv/conference/REEP/2017/Latvia-Univ-Agricult-REEP-2017_proceedings-151157.pdf 